\title{
Influence of Solvent on the Pore Structure and Activity of Pt-Sn/Alumino- Silicate Catalysts
}

\author{
M. Riad* and S. Mikhail \\ Egyptian Petroleum Research Institute, Nasr City, Hai Al-Zehour, P.O. Box 11727, Cairo, Egypt
}

\begin{abstract}
Kaolinite supported bimetallic Pt-Sn catalysts were prepared via impregnation technique using different solvents, water, ethanol and acetone. The catalysts were characterized by X-ray diffraction pattern and temperature programmed reduction techniques. Surface area and pore size distribution were determined by nitrogen physisorption technique. The activities of the catalysts were measured toward n-pentane isomerization reaction in a pulse micro-catalytic reactor operated under atmospheric pressure and at reaction temperature ranged from $200-450^{\circ} \mathrm{C}$. The results indicated that the selectivity of the Pt-Sn/kaolinite catalysts toward iso-pentane formation decreased from ethanol to acetone and then to water. Pore size distribution and diffusion coefficient of reactant and products are responsible for the high selectivity of $\mathrm{Pt}-\mathrm{Sn} /$ kaolinte (ethanol) catalyst towards iso-pentane formation.
\end{abstract}

Keywords: Kaolinite, Pt-Sn, catalyst, solvent, water, ethanol, acetone, pore structure.

\section{INTRODUCTION}

Isomerization of n-pentane has a great importance in the petroleum industry aimed to increase the octane number of gasoline [1]. It is known that, $\mathrm{Pt} / \mathrm{Al}_{2} \mathrm{O}_{3}$ was an effective catalyst for n-pentane and n-hexane isomerization reactions, but it has to be used at high reaction temperature, usually between $300-510^{\circ} \mathrm{C}$. To improve the performance and to lower the operation temperature of $\mathrm{Pt}$ catalyst, low temperature type bi-functional catalysts are used like $\mathrm{Pt} / \mathrm{Al}_{2} \mathrm{O}_{3}$ treated with $\mathrm{AlCl}_{3}$, which are capable of isomerization of $\mathrm{n}$ $\mathrm{C}_{5}$ and $\mathrm{n}^{-\mathrm{C}_{6}}$. Other bi-functional catalysts like Pt supported on zeolite or on alumino-silicate were developed by Riberio [2] and a high conversion (which was near to equilibrium value) was obtained upon them at reaction temperature $315^{\circ} \mathrm{C}$.

Kusakari et al. [3] studied the isomerization reaction of n-pentane over $\mathrm{Pt} / \mathrm{SiO}_{2}+\mathrm{H}$-Beta and $\mathrm{Pt} / \mathrm{SiO}_{2}+\mathrm{SO}_{4}{ }^{2-}-\mathrm{ZrO}_{2}$ catalysts at reaction temperature $320^{\circ} \mathrm{C}$ and found that the sulphated zirconium supported Pt catalyst was highly active towards iso-pentane formation.

Meanwhile Li et al. [4] established that $\mathrm{Pt} / \mathrm{WO}_{3} / \mathrm{ZrO}_{2} /$ SBA-15 was efficient catalyst towards $\mathrm{n}^{-\mathrm{C}_{5}}$ isomerization reaction compared with that supported on MCM-41 and silica gel, the reaction was performed at temperature $250^{\circ} \mathrm{C}$.

Lopez et al. [5] studied the same reaction using Pt/silicoalumino-phosphate molecular sieve catalyst at $500^{\circ} \mathrm{C}$ and atmospheric pressure. The catalyst showed high yield of pentene production.

Indeed, the incorporation of second metal (like Sn, Re and Ir) to platinum catalysts often provides additional catalytic stability, selectivity and or activity [6]. The effect of second metallic component can be very specific and depends

*Address correspondence to this author at the Egyptian Petroleum Research Institute, Nasr City, Hai Al-Zehour, P.O. Box 11727, Cairo, Egypt;

E-mail: maryriad2006@yahoo.com on the nature of metal dispersed over the support surface, the method employs to prepare the catalyst, the atomic ratio between the two metals and the type of reaction catalyzed the kind and state of support and the solvent used. The improvement of the properties of Pt phase in modified Pt- $(\mathrm{Sn}$, Ir or Re) catalysts toward the isomerization reaction can be traced back to the formation of alloys that can lead to a reduction in the size of Pt- supported particles, a lower in the coke formation and a higher selectivity towards the desirable products $[7,8]$.

Carvalho et al. [9] studied the isomerization of n-pentane on mono-, bi- and tri- Pt, Re and $\mathrm{Sn} / \gamma$ - alumina catalysts (at $500^{\circ} \mathrm{C}$, WHSV $=4.5, \mathrm{H}_{2}: \mathrm{n}-\mathrm{C}_{5}=6$ ) and found the addition of Sn affected the catalytic acid function and the activity for alkane isomerization and cyclization reactions. The addition of Re first increases the rate of undesirable reactions, which required strong acidity. Basic $\mathrm{SnO}_{\mathrm{x}}$ species are responsible for a decrease in number and strength of acid sites, while highly dispersed $\mathrm{ReO}_{\mathrm{x}}-\mathrm{AlO}_{\mathrm{y}}$ surface species increase the relative concentration of strong acid sites.

Supported Pt-Sn catalysts are usually prepared by impregnation of support by metal precursor solutions. Several solvents other than water have been proposed as ethanol [10] and acetone $[11,12]$ in the preparation of Pt-Sn catalyst, but a detailed study concerning their effect on the properties of the catalysts is still lacking. In addition the experimental conditions vary widely in these works, and thus one cannot conclude about the effect of the solvent itself. Therefore, a systematic study in which all the variables are kept constant, except the solvent is necessary.

This work aimed to study the influence of solvent (water, ethanol and acetone) used for preparing $\mathrm{Pt}-\mathrm{Sn} / \mathrm{kaolinite}$ catalysts on their crystallite size, pore size distribution and in particular on their activity and selectivity toward isomerization reaction of $n$-pentane. 


\section{EXPERIMENTAL}

\section{1- Preparation of Catalysts}

Kaolinite with silica-alumina ratio: 2.3 from Mussaba Salama district, Sinai Pennsylvania "previously washed with $2 \%$ hydrochloric acid [13]", was used as support for preparing bimetallic Pt-Sn catalysts.

$\mathrm{Pt}-\mathrm{Sn} /$ kaolinite catalysts containing equal amounts of $(0.3$ $w t \%$ based on support weight "100gm") Pt and Sn were prepared via the conventional impregnation technique using solutions of chloroplatinic acid $\left(\mathrm{H}_{2} \mathrm{PtCl}_{6} . \mathrm{H}_{2} \mathrm{O}, 0.0098\right.$ mol.L $\left.\mathrm{L}^{-1}\right)$ and tin chloride $\left(\mathrm{SnCl}_{2} .4 \mathrm{H}_{2} \mathrm{O}, 0.0140 \mathrm{~mol} . \mathrm{L}^{-1}\right)$, acidified with $0.3 \mathrm{~cm}^{3} \mathrm{HCl}\left(12 \mathrm{~mol}^{-\mathrm{L}^{-1}}\right)$ and water (w "1000 ml"), ethanol (e "1000 ml") and acetone (a "1000 ml") were used as solvents. Before the impregnation, the support was wet with the corresponding solvents. The impregnated catalysts kept in a rota-evaporator for 16 hours to prevent phase separation. The prepared catalysts dried at $120{ }^{\circ} \mathrm{C}$, calcined for 4 hours at $450{ }^{\circ} \mathrm{C}$ under flowing of dry air and then reduced at $400{ }^{\circ} \mathrm{C}$ in hydrogen stream for 4 hours.

\section{2- Catalysts Characterization}

-X-ray diffraction pattern analysis (XRD) was investigated in the range $2 \theta=4-80^{\circ}$, in a Brukur B8 advance diffractometer with $\mathrm{CuK} \alpha$ radiation. The instrument was operated at $40 \mathrm{KV}$ and the spectra were recorded at a scanning speed of $8^{\circ} / \mathrm{min}$, the slits sizes were $1^{\circ}, 1^{\circ}, 3^{\circ}$ and the dimension of the sample holder was $1.5 \mathrm{~cm}$ width X $2 \mathrm{~cm}$ length. The apparatus was provided with program to calculate the crystallite size of the studied catalysts using Sherrer equation.

-Temperature-programmed reduction (TPR) was carried out using a Micromeritics CHEMBET-3000 TPR/TPD system. The catalysts were first pretreated in a flow of $\mathrm{N}_{2}$ at $500^{\circ} \mathrm{C}$ for $1 \mathrm{~h}$, and then cooled to room temperature in $\mathrm{N}_{2}$ atmosphere. The catalysts reduced in a mixture of $10 \% \mathrm{H}_{2}$ in nitrogen with flow rate $55-\mathrm{cm}^{3} \mathrm{~min}^{-1}$, at increasing temperature programmed to a rate of $10^{\circ} \mathrm{C} / \mathrm{min}$ up to $1000^{\circ} \mathrm{C}$. Catalyst weight used for TPR measurements was about $0.1 \mathrm{gm}$.

-Nitrogen physisorption isotherms were measured using Quantachrome Nova Automated Gas Sorption apparatus. The sample was out gassed at $300^{\circ} \mathrm{C}(10-4 \mathrm{~Pa})$, surface area was calculated from adsorption curve by BET method and pore size distribution from the desorption curve.

\section{3- Catalytic Activity}

The catalytic isomerization reaction of n-pentane was performed in a pulse micro-reactor constructed by modifying a gas chromatographic assembly by introduction of a stainless steel tube between the sample inlet and the analytical column.

The activities of the prepared catalysts measured by carrying out the reaction at temperature ranged from $200-450^{\circ} \mathrm{C}$ under atmospheric pressure. Each experiment used $0.5 \mathrm{~g}$ of dried catalyst held in place by glass wool. A $2-\mu l$ pulse of the reactant is injected into the reactor bed through a septum near the reactor inlet. Hydrogen stream was flowing continuously down the catalyst bed at a rate of $40 \mathrm{ml} / \mathrm{min}$. Each experiment was repeated for 3-times for reproducibility. The reaction products are immediately analyzed through a chro- matographic column (silicon oil-550) directly attached to the reactor, the column is packed with chromosorb b 80-100 mesh size.

\section{RESULT AND DISCUSSION}

\section{Formation of Complex in Different Solvents}

When the aqueous solution of stannous chloride added to chloroplatinic acid one, a change of color from yellow (typical of the platinum solution) to yellowish - brown was noted, besides the precipitation of a brown solid. After the addition of $\mathrm{HCl}$, the brown solid completely dissolved and the solution remained yellowish brown. This color is characteristics of a tin-platinum complex, trans- $\mathrm{PtCl}_{2}\left(\mathrm{SnCl}_{3}\right)_{2}{ }^{2-}$, which is stable in acidic medium $[14,15]$. It is known that this complex is slowly transformed into cis- $\mathrm{PtCl}_{2}\left(\mathrm{SnCl}_{3}\right)_{2}{ }^{2-}$ as the acidity of the medium decreases and the color of the solution changes to yellow. In the preparation carried out in ethanol, the solution color changed from yellow to orange and no solid produced. In acetone, the solution color changed from yellow to orange but immediately came back to yellow. This observing indicates that, in aqueous solution the complex is mainly in the trans- form whereas in ethanol or in acetone solutions it exists mainly in the cis-form [16]. This can be explained by considering that water is more acidic than ethanol that in turn is more acidic than acetone.

\section{X-Ray Diffraction Pattern}

X-ray diffraction pattern for support and reduced Pt-Sn /kaolinite catalysts using water, ethanol and acetone were presented in Fig. (1).

Kaolinite main lines were detected at d-spacing: 7.17, 4.44 and $3.56 \AA$ (ASTM 05-0143). Meanwhile, lines characterize the $\mathrm{Pt}-\mathrm{Sn}$ species were not detected due to the high dispersion of low amounts of Pt-Sn species on the kaolinite support.

Moreover, the pattern revealed an observed increase in the intensity of the kaolinite main lines on using the different solvents, it increased from water to acetone then to ethanol respectively (with an intensity ratios 13: 15.6: 16.8 at dspacing: 7.17), which may relate to the difference in the adsorption between the three solvents used and the size of the formed particles that may block the different support sites and then partially screen the kaolinite main lines.

\section{Crystallite Size}

The crystallite size for Pt-Sn/kaolinite catalysts using three solvents was estimated using Sherrer formula at $2 \theta=$ $7.15^{\circ}$. The crystallite size increased from 9.0 to 12.0 and then to $16.0 \mathrm{~nm}$ for Pt-Sn/kaolinite (ethanol) to (water) then to (acetone) respectively. This behavior can be explain by considering that: kaolinite support in acidic medium adsorbs $\mathrm{PtCl}_{6}{ }^{2-}$ (from chloroplatinic acid $\mathrm{H}_{2} \mathrm{PtCl}_{6} \cdot \mathrm{H}_{2} \mathrm{O}$ ) as well as polar molecules like water, acetone and ethanol that have dipole moment $(1.85,2.88$ and $1.69 \mathrm{D}$ respectively). The adsorption will be stronger as the dipole moment increases which have an effect on the drying step of the impregnated catalysts. If this step is fast (in case of acetone $\mathrm{BP}=56.0^{\circ} \mathrm{C}$ ) a fast precipitation of the metal will take place resulting in a low homogeneity of the metal crystallites on kaolinite surface [17]. 


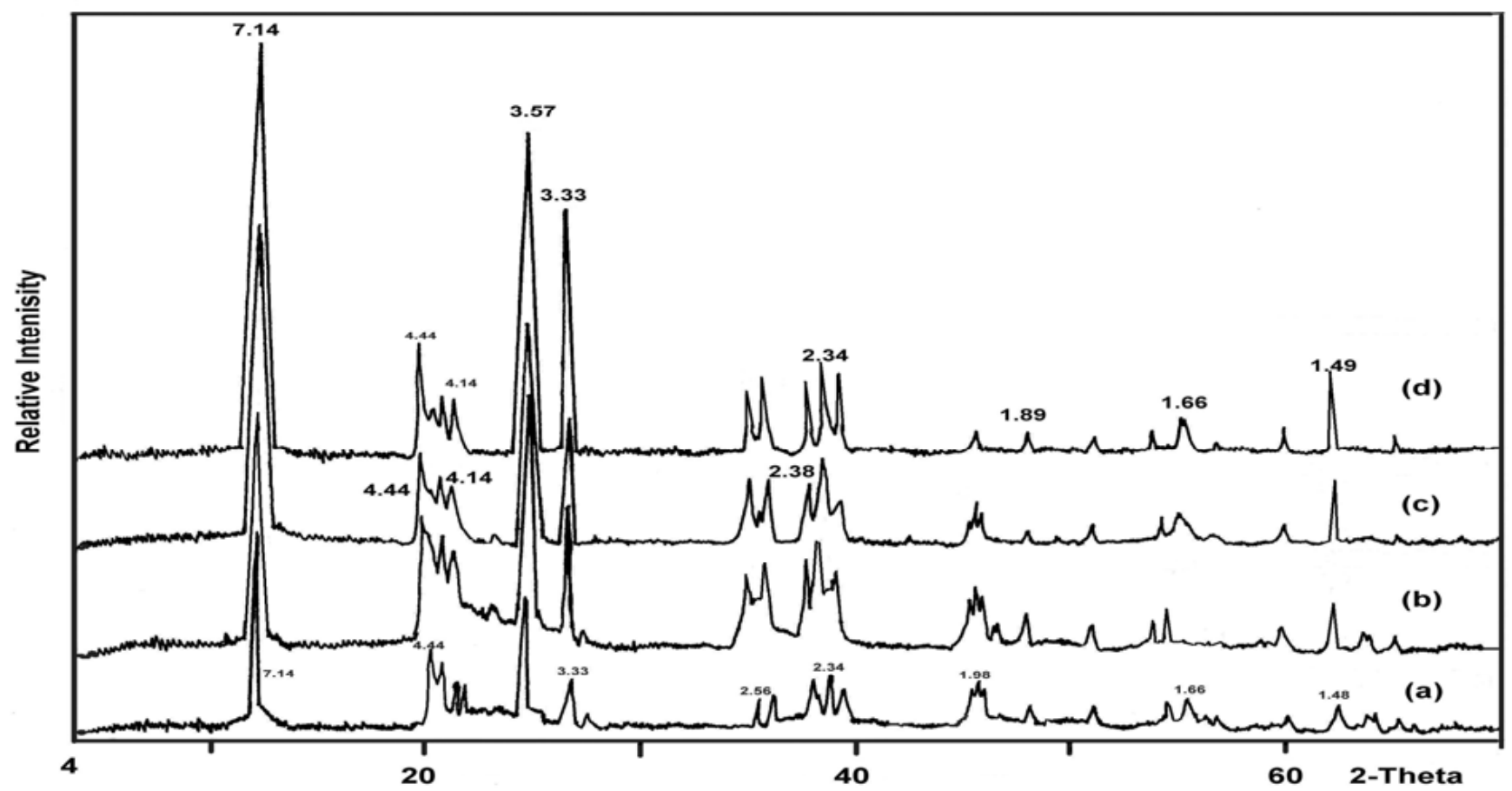

Fig. (1). X-ray Diffraction Pattern for Reduced Pt-Sn/kaolinite Catalysts: (a) Kaolinite (b) Water (c) Acetone (d) Ethanol.

Moreover, particles dissolved in solvents have high dielectric constant (like water and ethanol), will have a low tendency to attract and associate into aggregates and then precipitate as larger particles; acetone has the lowest dielectric constant compared with water and ethanol [17].

Accordingly, Inui and Miyake [18] reported a superior homogeneity of Pt-Sn in catalysts prepared using water compared to the catalysts prepared in acetone. It can also noted that the crystallite size of catalyst prepared in water is higher than that prepared in ethanol, this is due to the sintering produced by the water during catalyst activation where ethanol is faster evaporated than water to leave more dispersed smaller size Pt-Sn species, as stated by Huang and Fung [19].

\section{Reduction Behavior}

Temperature programmed reduction profiles for calcined $\mathrm{Pt}-\mathrm{Sn} /$ kaolinite catalysts in water, ethanol and acetone were presented in Fig. (2).

For Pt-Sn (water) /kaolinite catalyst, two peaks were observed at $280{ }^{\circ} \mathrm{C} \& 550{ }^{\circ} \mathrm{C}$ (Fig. 2a). The first peak attributed to the reduction of $\mathrm{Pt}$ and $\mathrm{Sn}$ species and the formation of an alloy, in agreement with Balakrishman and Schwank study [20] who detected the reduction peak of Pt-Sn species at $280-300^{\circ} \mathrm{C}$, on using $\mathrm{Pt}-\mathrm{Sn} / \mathrm{Al}_{2} \mathrm{O}_{3}$ catalyst. The second higher temperature reduction peak centered at $\sim 550^{\circ} \mathrm{C}$ indicated reduction of segregated $\mathrm{Sn}$ surrounded some Pt crystals as postulated by Humblot et al. [21]. This profile was similar to that presented by Lieske and Volter [22] and Kappenstein et al. [23] for Pt-Sn/alumina catalyst.

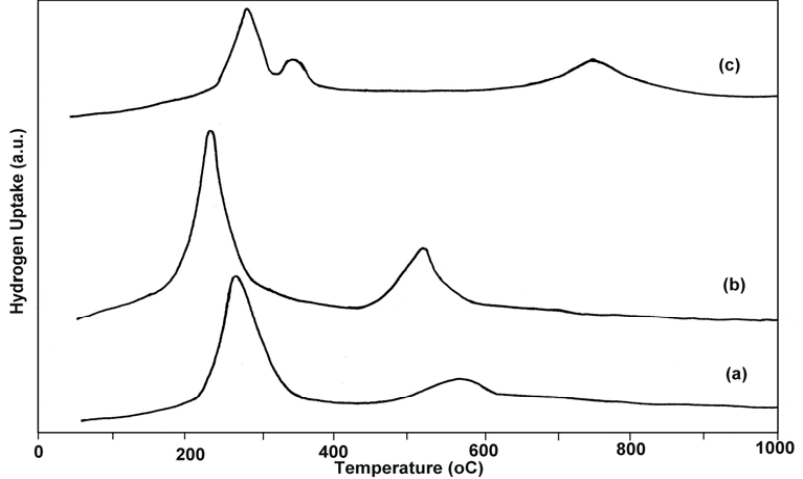

Fig. (2). Temperature Programmed Reduction Profiles for PtSn/Kaolinite: (a) Water (b) Acetone (c) Ethanol.

Pt-Sn (acetone)/kaolinite in Fig. (2b), showed a larger peak area compared with that prepared in water. This means, the crystal oxides of $\mathrm{Pt}-\mathrm{Sn} /$ kaolinite in acetone consume more hydrogen to reduce which may result from that, the crystal formed on using acetone had larger size compared with Pt-Sn (water).

When ethanol was used as solvent, TPR profile of Pt$\mathrm{Sn} /$ kaolinite showed one peak at $\sim 280^{\circ} \mathrm{C}$ with shoulder at $\sim 320{ }^{\circ} \mathrm{C}$, suggesting the existence of a strong Pt-Sn interaction being likely the formation of an alloy (the platinum-tin interaction depends on the stability of the formed bimetallic complex [12]). This observation can be assigned to the higher acidity of the ethanol solution as compared to the acetone one, which led to a more stable bimetallic complex [14]. Meanwhile, this behavior was not observed for Pt-Sn (water)/kaolinite in spite of the high acidity of water, this is due 
to the hydrolysis of stannous chloride may take place during the impregnation step and lead to the destruction of bimetallic complex [11].

\section{Surface Properties}

The different surface characteristics for Pt-Sn/kaolinite catalysts using different solvents were determined from low temperature nitrogen adsorption isotherms conducted at 196. These characteristics included specific surface area $\left(\mathrm{S}_{\mathrm{BET}}\right)$, total pore volume $\left(\mathrm{V}_{\mathrm{p}}\right)$ and average pore radius $\left(\mathrm{r}_{\mathrm{H}}\right)$, the data included in (Table 1). Nitrogen adsorptiondesorption isotherms (Fig. 3) for the studied catalysts are of type II based on Brunauer's classification [24] and exhibiting H3 hysteresis loop (according to IUPAC classification). All adsorption isotherms are type I at low pressures indicating a micro-pore filling process and are multilayer adsorption at higher pressures, which implies a certain amount of mesoporosity. Hysteresis loop observed in all catalysts which exhibiting no limiting adsorption at high $\mathrm{P} / \mathrm{P}_{\mathrm{o}}$ ratio is observed with aggregate of plate -like particle giving rise to slit shaped pore.

Data in Table 1 indicated that, the surface area of calcined Pt-Sn (different solvents) catalysts decreased upon the reduction. This decrease related to the formed Pt-Sn ensembles redistributed their self to anchor at different support sites that may cause widening of some narrow pores and blocking of another as confirmed from the increase of average pore radius with a decrease in pore volume.

Table 1. Surface Properties for Pt-Sn/kaolinite Catalysts in Different Solvents

\begin{tabular}{|c|c|c|c|c|c|c|}
\hline Catalyst & Pt-Sn $n_{(w)}$ Calcined & Pt-Sn $n_{(w)}$ Reduced & Pt-Sn ${ }_{(\mathrm{e})}$ Calcined & Pt-Sn $_{(\mathrm{e})}$ Reduced & Pt-Sn $_{(\mathrm{a})}$ Calcined & Pt-Sn $_{(\mathrm{a})}$ Reduced \\
\hline $\mathrm{S}_{\mathrm{BET}}\left(\mathrm{m}^{2} / \mathrm{g}\right)$ & 26.8 & 15.3 & 23.0 & 15.0 & 20.0 & 9.0 \\
\hline $\mathrm{P}_{\mathrm{V}}(\mathrm{ml} / \mathrm{g})$ & 0.024 & 0.013 & 0.021 & 0.012 & 0.016 & 0.01 \\
\hline $\mathrm{r}_{\mathrm{H}}(\mathrm{nm})$ & 1.0 & 2.2 & 1.4 & 2.6 & 1.6 & 2.8 \\
\hline
\end{tabular}
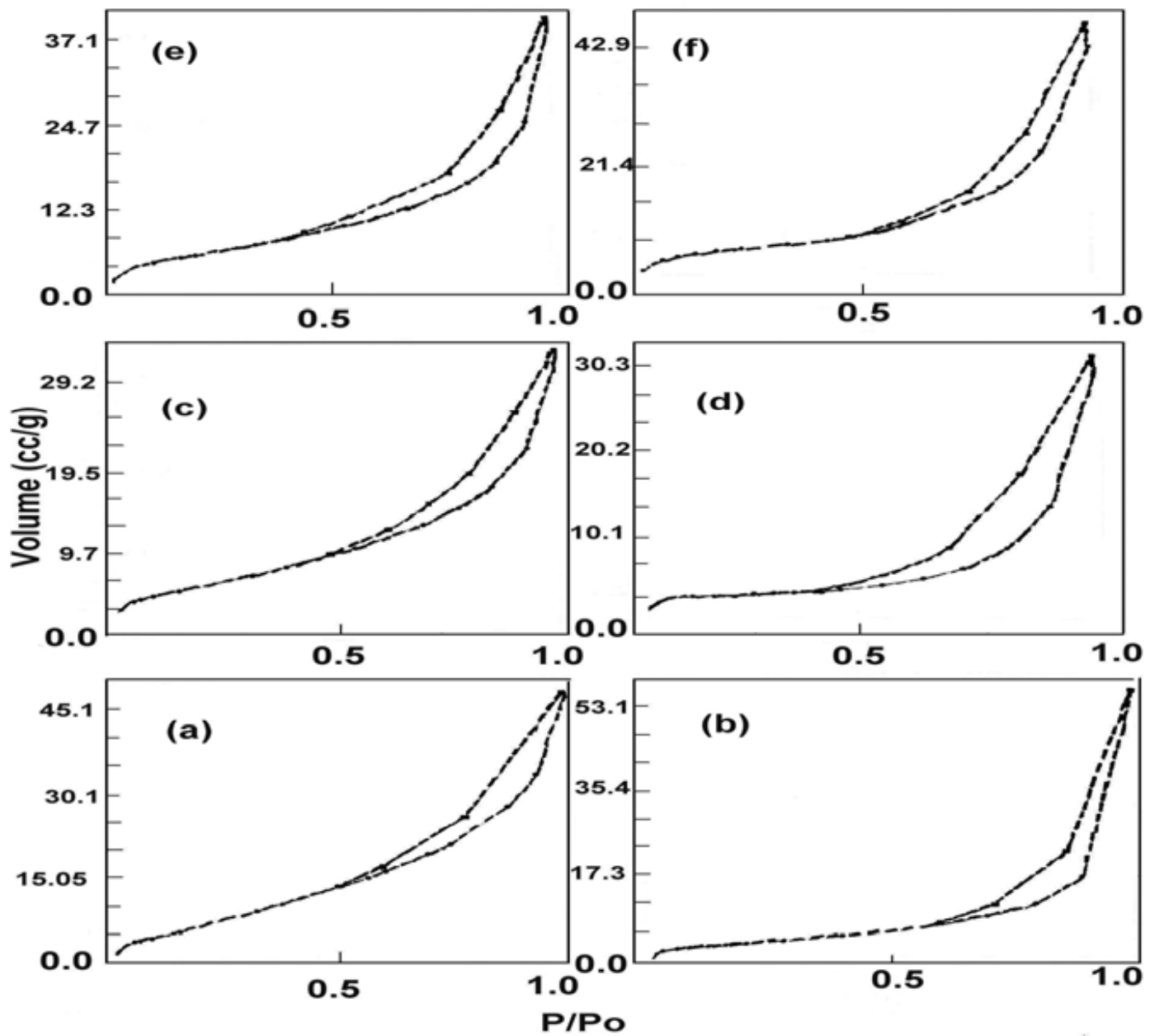

(b)

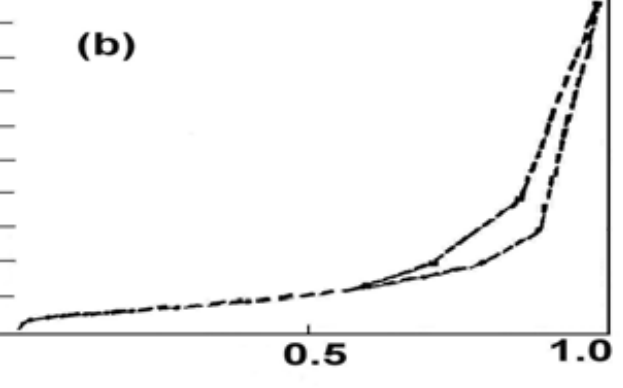

Fig. (3). $\mathrm{N}_{2}$ Adsorption-Desorption Isotherms for: (a) Calcined Pt-Sn ${ }_{(w)}$ (b) Reduced Pt-Sn $n_{(w)}$ (c) Calcined Pt-Sn ${ }_{(e)}$, (d) Reduced Pt-Sn (e) $($ e) Calcined Pt-Sn (a), (f) Reduced Pt-Sn (a). 
Meanwhile, the surface area of reduced Pt-Sn catalysts was the same on using water and ethanol $\left(15.0,15.0 \mathrm{~m}^{2} / \mathrm{g}\right)$ but showed a low value $9.0 \mathrm{~m}^{2} / \mathrm{g}$ on using acetone.

Pt-Sn (ethanol)/kaolinite catalyst had the lowest crystallite size, which led to a uniform dispersion of Pt-Sn species and consequently an increase in the surface area in comparing with Pt-Sn (acetone) catalyst. Meanwhile, larger Pt-Sn (acetone) aggregates may plug the mouth of micropores and or widening some narrow pores that responsible for the decrease in surface area (as observed in pore size distribution data).

The pore system was identified by t-method of de Boer et al. [25], the $\mathrm{S}_{\mathrm{t}}$ values showed agreement with the corresponding $\mathrm{S}_{\mathrm{BET}}$ values. $\mathrm{V}_{1^{-}} \mathrm{t}$ plots of the studied catalysts were presented in Fig. (4), and showed an upward deviation that characterized meso-porous material and corresponded to capillary condensation due to adsorbate-adsorbate interaction.

For reduced $\mathrm{Pt}-\mathrm{Sn}$ (water) catalyst, $\mathrm{V}_{\mathrm{1}} \mathrm{t}$ plot displayed upward deviation starts at $\mathrm{t}=0.6 \mathrm{~nm}$ i.e. $\mathrm{P} / \mathrm{P}_{\mathrm{o}}=0.45$ that similar to hysteresis closure point at $\mathrm{P} / \mathrm{P}_{\mathrm{o}}=0.55$ (Fig. 3d). This is an indication for predominate of meso-pores and absence of micro-pores. Meanwhile, for Pt-Sn (ethanol \& acetone) the upward deviation started at $\mathrm{t}=0.7 \& 0.75 \mathrm{~nm}$ i.e. $\mathrm{P} / \mathrm{P}_{\mathrm{o}}=0.6$ $\& 0.65$, whereas the hysteresis closure point was at $\mathrm{P} / \mathrm{P}_{\mathrm{o}}=0.5$ $\& 0.55$. Such delay indicated the presence of wide mesopores.

\section{Pore Size Distribution}

Pore size distribution for the calcined and reduced Pt-Sn (different solvents) catalysts was investigated using $\mathrm{N}_{2}$ phy- sisorption technique from the desorption curve and illustrated in the form of $\mathrm{dV} / \mathrm{dD}$ vs diameter $(\AA)$. Data were illustrated in Fig. (5).

Pore size distribution for calcined Pt-Sn (different solvents) catalysts was tending to shift to wider pore diameter upon reduction. Metallic particles anchored to less stable surface groups that probably become mobile during the reduction step and may find other free anchoring sites on the wall of the meso-pores structure with losses in dispersion with different extent and resulting in pore widening.

Pore size distribution for reduced Pt-Sn (water) catalyst (Fig. 5b), behaved bi-modal pore size at diameter 163.5 and 181.0 A. Meanwhile, pore distribution for Pt-Sn (ethanol) catalyst shift towards wider pore at diameter 175.5 and 219.0 A. Pt-Sn (acetone) catalyst behaved mono-modal wide pore distribution at diameter $245.0 \AA$.

This difference in pore distribution was due to, Sn had a lone electron pairs on "s" orbital that interact with more extent with less acidic ethanol and acetone than with more acidic water. Thus, the evaporation of solvent resulted in the formation of pore structure with different diameters.

In addition, when water used as solvent, the impregnated complex presents in trans-form that facilitated its penetration inside support pores. Then, upon calcination and reduction steps, Pt-Sn species accumulated on the pore walls to produce narrow pores. Meanwhile, Pt-Sn species in ethanol and acetone (cis-form) were strained due to the steric hindered induced by two $\mathrm{SnCl}_{3}$ groups in $\mathrm{PtCl}_{2}\left(\mathrm{SnCl}_{3}\right)_{2}{ }^{2-}$ complex, then the repulsion forces will induce random distribution of particles that may cause enlarging of pores and produce more wide pores, in agreement with the surface textural data.

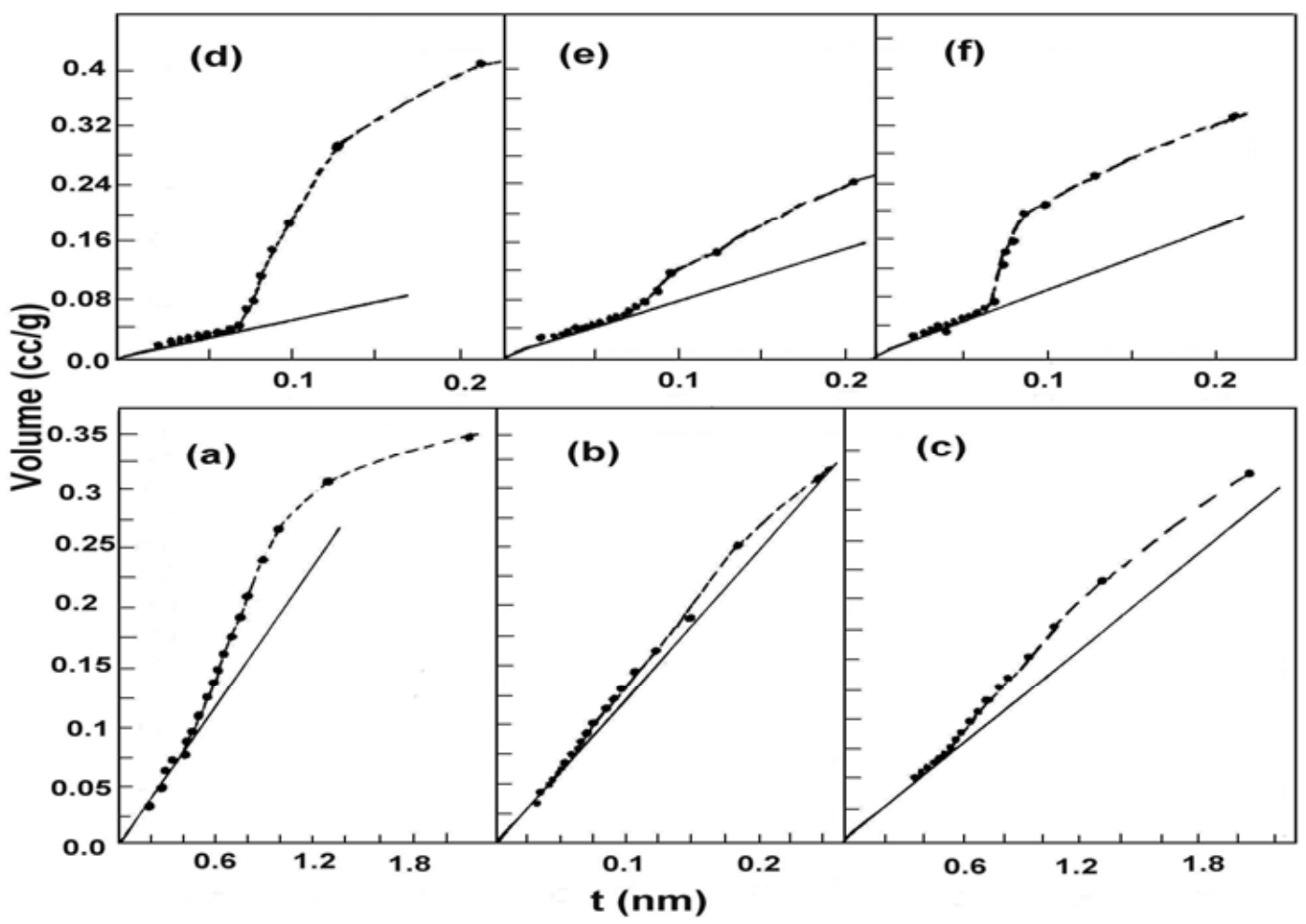

Fig. (4). $\mathrm{V}_{1}$-t Plot for Pt-Sn/kaolinite: (a) Calcined Pt-Sn (w) $($ b) Calcined Pt-Sn (e) (c) Calcined Pt-Sn (a), (d) Reduced Pt-Sn (w) $($ e) Reduced Pt$\mathrm{Sn}_{(\mathrm{e})}(\mathbf{f})$ Reduced Pt-Sn (a). 
(a)

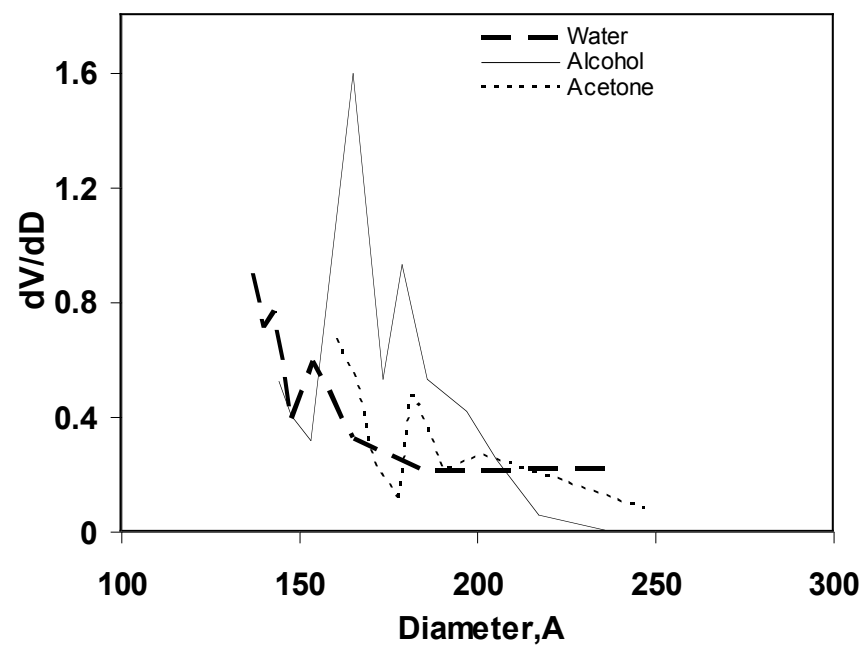

(b)

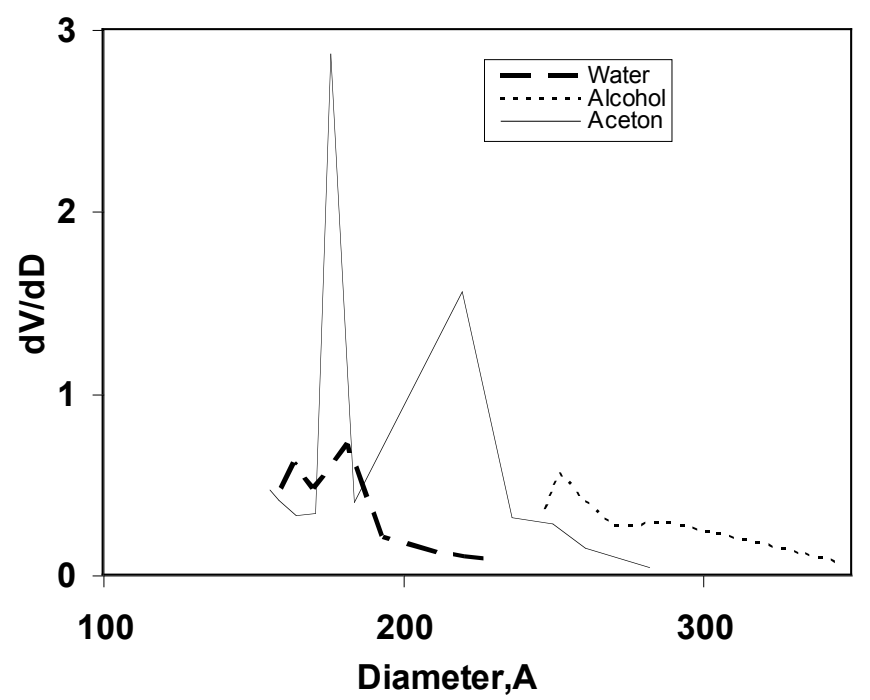

Fig. (5). Pore Size Distribution for Pt-Sn/ kaolinite Catalysts in Different Solvents: (a) Calcined (b) Reduced.

To explain the effect of solvent on surface roughness of the reduced Pt-Sn/ kaolinite catalysts, the surface fractal dominion $\mathrm{D}$ estimated and compared through the nitrogen isotherm with the aid of a fractal version of the Frenkel- HleyHill (FHH) equations. The classical FHH theory for multilayer adsorption was extended to the fractal surfaces.

$\mathrm{N} / \mathrm{N}_{\mathrm{m}}=\left[\mathrm{RT} \ln \mathrm{P}^{0} / \mathrm{P}\right]^{-1 / \mathrm{m}}$

where $\mathrm{N} / \mathrm{N}_{\mathrm{m}}$ represented the fraction of surface coverage, $\mathrm{P}$ and $\mathrm{P}_{0}$ are respectively the equilibrium and saturation pressures of the adsorbate. Two types of fractal isotherm equations were proposed [26]. If van der Waals attraction between the solid and the adsorbed film was the dominant factor, the $\mathrm{D}$ values can be estimated as:

$\mathrm{D}=3[1-1 / \mathrm{m}]$

Conversely, if the liquid /gas surface tension (capillary force) was more important, the $\mathrm{D}$ value calculated from equation (2):

$\mathrm{D}=3-1 / \mathrm{m}$
The nitrogen desorption isotherms of the studied catalysts indicated the capillary condensation in the meso-pore range, so D value should estimated from equation (2).

Usually, the surface fractal dimension $\mathrm{D}$ lies between 2 and 3. For a regular and smooth surface $D=2$, higher $D$ value suggests greater roughenss and surface spaces to be filled. The values for the examined catalyst were distinct indicating that the surface roughness for the catalysts was different. When acetone (large crystallite size) was used as solvent the surface screening effect may be a key factor heading to the smaller BET surface area found in Pt-Sn catalyst since the D value were high value (2.7). In addition acetone covered some extent of the support pores and on calcination and reduction leaving more space to be filled i.e. more wide pores were created, in agreement with the pore size distribution results.

However when water and ethanol was used the pore opening effect was predominant heading to the increase in BET surface area because the D value became smaller compared with acetone one ( 2.55 and 2.35 respectively).

\section{Catalytic Activity}

The catalytic activity of the studied catalysts Pt-Sn (different solvents)/kaolinite were studied via n-pentane isomerization reaction, the products distribution for the studied catalysts were presented in Fig. (6). The main products were $\mathrm{C}_{1}-\mathrm{C}_{4}$ cracked products, iso-pentane, iso-hexane in addition to n-hexane. The isomerization mechanism for Pt-Sn catalysts was a bi-functional one [27], where the reaction had begun with paraffin dehydrogenation on the metallic sites then, the olefin so produced isomerized on the acid sites and the iso- olefin hydrogenated on the metal sites. The reaction mechanism controlled by the acid function and the formation of iso-pentane can be taken as a measure of that function [27]. Lui et al. [28] stated that, the isomerization reaction was performed via inter-molecular mechanism where adsorbed $\mathrm{C}_{5}^{+}$reacts with a pentene molecule to form an adsorbed $\mathrm{C}_{10}{ }^{+}$ion.

$\mathrm{n}-\mathrm{C}_{5} \mathrm{H}_{10}+\mathrm{C}_{5} \mathrm{H}_{11}{ }^{+}=\mathrm{C}_{10} \mathrm{H}_{21}{ }^{+}$

These ions undergo $\beta$-fission to form $C_{6}$ and $C_{4}$ fragments or can isomerize and give two $\mathrm{i}-\mathrm{C}_{5}$ fragments.

In addition, the selectivity to iso-pentane can be taken as representative of the acid function intermediate strength, the selectivity to propane $\mathrm{C}_{3}$ as representative of the strong acid sites, the selectivity to methane $\mathrm{C}_{1}$ as representative of the metal function activity (hydrogenolysis).

The isomerization activity towards iso-pentane formation for the studied catalysts increased as the reaction temperature increased and reached its maximum values at $400{ }^{\circ} \mathrm{C}$ then it decreased due to cracking reaction [27].

The yield value of iso-pentane increased from (32.0\%) for Pt-Sn (water)/ kaolinite, followed by acetone (34.0\%) and then ethanol (39.5\%) (Fig. 6). Bishara et al. [29] assigned the higher activity of Pt-Sn catalyst prepared in acetone compared with that in water to its high chloride content, where most of chlorine was lost during the steps of calcination and reduction of the catalysts. As acetone has lower boiling point as compared to water most of acetone eliminated at lower temperature at which only small amount can 


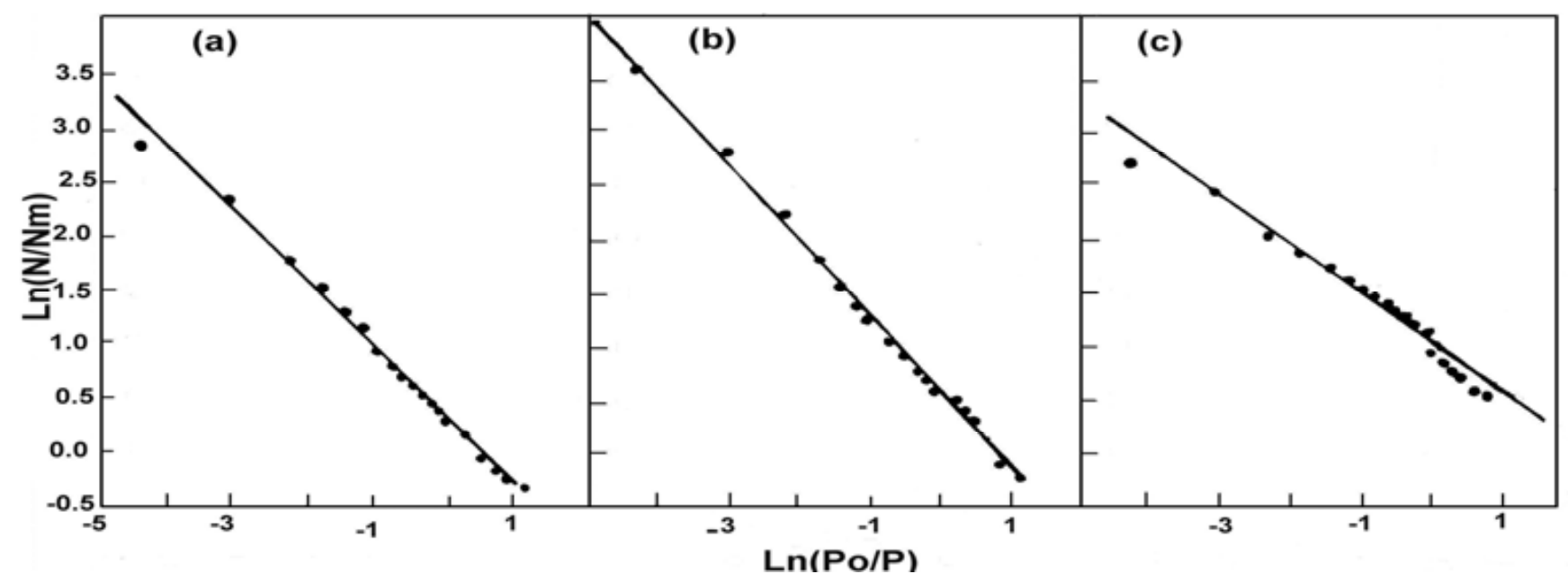

Fig. (6). Fractal Behavior of Pt-Sn/ kaolinite Catalysts: (a) Ethanol (b) Water (c) Acetone.

be eliminated. Water eliminated at temperature high enough to leach chloride from the solid.

Data in Table 2 indicated that, the selectivity to $\mathrm{C}_{1}$ is nearly the same $(\sim 0.9 \%)$ on using the three catalysts i.e. the change of solvent had no effect on the metallic function.

Different authors explained the low selectivity of Pt-Sn catalysts toward $\mathrm{C}_{1}$ formation. Paal et al. [7], stated that lower selectivity of Pt-Sn catalyst to produce hydrogenolysis product can be explained taking into account that tin decreased the number of contiguous $\mathrm{Pt}$ atoms, dividing the $\mathrm{Pt}$ surface into smaller ensembles, in this way limiting the adsorption of hydrocarbon molecules on the metal i.e. hydrogenolysis can be reduced and lead to an increase in the selectivity to the isomeriztion products.

The selectivity to $C_{3}$ decreased from 5.0 to 3.5 then to 2.9 $\%$ on using water, ethanol and acetone respectively. That indicated the acidity of Pt-Sn catalyst decreased in this sequence with decrease in the hydrocracking products, in agreement with the results of selectivity of iso- $\mathrm{C}_{6}$ (formed via disproportionation reaction on the acid sites) that increased from water to ethanol then to acetone.

Meanwhile, the selectivity to iso- $\mathrm{C}_{5}$ increased from 53.8 to 57.7 then to $66.0 \%$ on using acetone, water and alcohol respectively.

Generally, the narrow pore size distribution has the function for shape selection of reactant and product. In other word, it favors the isomerization but not the cracking reactions as explained by Salmones et al. [30]. In addition, Sharma et al. [31] stated that, the meso-pores in 100-200 $\AA$ diameter range have an effect on the catalytic reaction of Pt-
Sn catalyst and they contribute more to the pore volume. Van Brockhoven et al. [32] assigned that the wide meso-pore structure promoted the rate of dissociative desorption of npentane.

Therefore, the selectivity to iso- $\mathrm{C}_{5}$ increased from 53.8 (for wide pores $\mathrm{Pt}-\mathrm{Sn}$ in acetone) to $57.7 \%$ (for narrow meso-pores $\mathrm{Pt}-\mathrm{Sn}$ in water) and the isomerization reaction was textural sensitive reaction.

But in narrow meso-pores, the probability of accumulation of $n-C_{5}$ conversion products on the catalyst walls is predominant that might block the pore mouth resulting in difficulty of diffusion of the isomerized products as indicated from the decrease in catalytic activity and selectivity of Pt$\mathrm{Sn}$ (water) /kaolinte towards iso-pentane formation, as compared with ethanol one.

The results of catalytic activity were supported with the data of diffusion of reactant molecule in meso-pores as described with Knudsen equation [33].

$\mathrm{D}=2 / 3 \mathrm{r}_{\mathrm{p}}[8 \mathrm{RT} / \Pi \mathrm{M}]^{1 / 2}$

where $\mathrm{D}, \mathrm{r}_{\mathrm{p}}, \mathrm{R}, \mathrm{T}$ and $\mathrm{M}$ are respectively diffusion coefficient in pores, pore radius, gas constant, temperature and molecular weight of gas molecules. The smaller the mesopore size is, the smaller the diffusion coefficient becomes. Thus, gas molecules will require long time to move into the center of catalyst particles with large size and with small pores in which diffusion coefficient is also small. Then the center portion of catalyst particles does not effectively work in reaction.

Table 2. Results of n-Pentane Reaction on Pt-Sn (Different Solvents) / Kaolinite at Reaction Temperature $400^{\circ} \mathrm{C}$

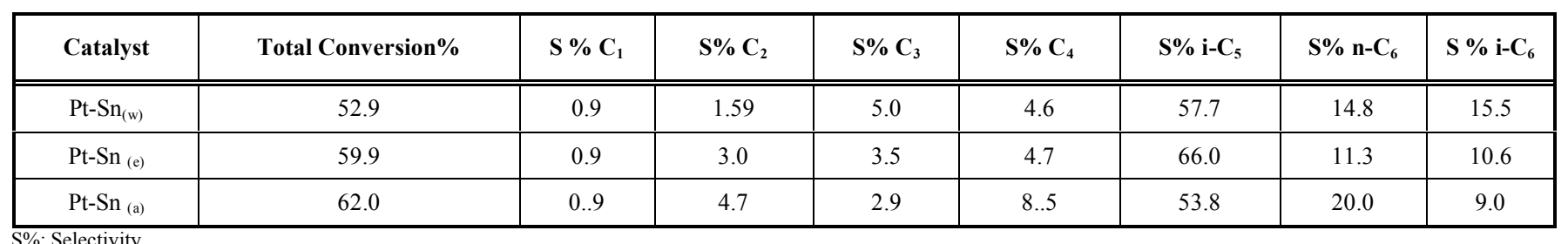



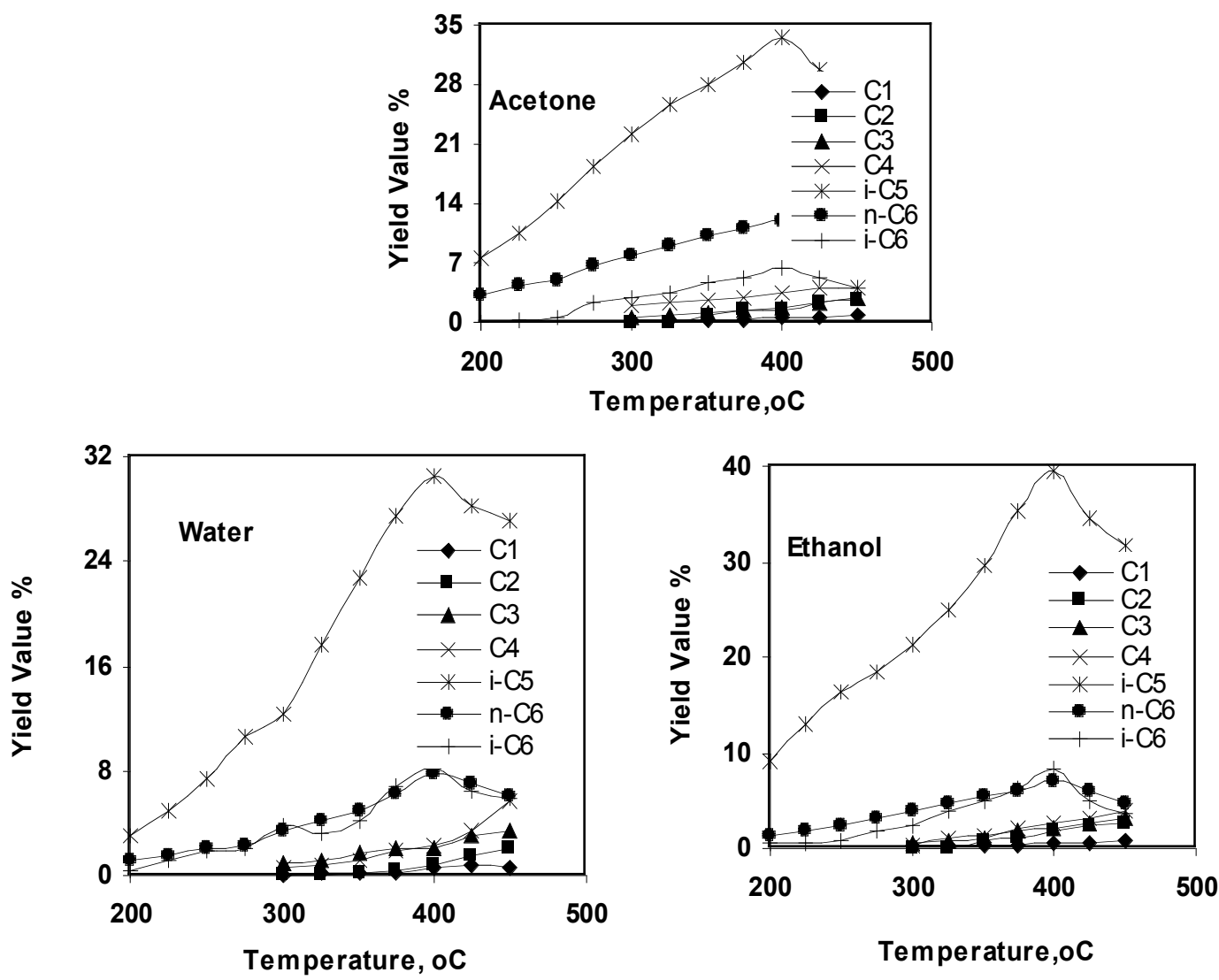

Fig. (7). Conversion of n-pentane on Pt-Sn/kaolinite Catalysts.

The diffusion coefficient increased from 36.6 to 43.0 then to 45.5 on using water, ethanol and acetone respectively. Pores of Pt-Sn in water restricted the diffusion of reactant molecules. Meanwhile, more wide pores (Pt-Sn in ethanol) enhanced it i.e. the easiest diffusion of gaseous reactant and products in large pores probably accounted for its high selectivity, in agreement with the results of catalytic activity.

Pt-Sn in acetone had mono-modal wide meso-pore at diameter $245 \AA$ and high diffusion coefficient that was not selective for the diffusion of the isomerizatoion products, thus it showed the least selectivity toward iso-pentane formation compared with the other solvents.

\section{CONCLUSION}

From the previous results, it can be concluded that: the type of solvents (water, acetone and ethanol) used during the impregnation step affect the crystallite size, surface area, pore structure and then the catalytic activity of Pt$\mathrm{Sn} /$ kaolinite catalysts as confirmed from:

1. The size of Pt-Sn/kaolinite crystallites (calculated using Sherrer equation) decreased from water to acetone then to ethanol, which depended on the differences in the dipole moment and dielectric constant.

2. The surface area of Pt-Sn (acetone)/kaolinite catalyst was the lowest one $\left(9.0 \mathrm{~m}^{2} / \mathrm{g}\right)$ compared to the other two solvents. Which may be due to the formation of Pt-Sn (acetone) aggregates, that widening some nar- row pores and responsible for the decrease in surface area.

3. Pore size distribution shows that, Pt-Sn (acetone) posed the widest pore size at diameter $245.0 \AA$.

4. The highest selectivity for Pt-Sn (ethanol)/kaolinite catalyst towards iso-pentane formation $(66.0 \%)$ compared with the other two solvents was based on the pore structure and the facility to desorb $\mathrm{i}-\mathrm{C}_{5}$ as confirmed from the diffusion coefficient results.

\section{REFERENCES}

[1] Bour, G.; Schwoerer, C. P.; Asselin, G. F. The oxidation state of tin and the interaction between platinum and tin. Oil Gas J., 1970, 68, 43-49.

[2] Ribeiro, F. R. Nato Advanced Study Institute on Zeolite Science and Technology, Alcabideche, Portugal.

[3] Kusakari, T.; Tomishige, K.; Fujimoto, K. Micro-calorimetric and kinetic studies of silica supported platinum-tin catalyst for isobutane dehydrogenation. Appl. Catal. A, 2002, 224, 219-229.

[4] Li, T.; Wong, S-T.; Chao, M-C.; Lin, H-P.; Mou, C-Y.; Cheng, S. Alloy formation in supported Pt-Sn catalysts. Appl. Catal. A, 2004, 261,211-218.

[5] Lopez, C. M.; DeSousa, M.; Campos, Y.; Hermandez, L.; Garcia, L. Paraffine isomerization on supported platinum-tin catalysts Appl. Catal. A, 2004, 258, 195-199.

[6] Sinfelt, J. H. In: Anderson, J.R.; Boudart, M.; (Eds), Catalysis : Science and Technology, Springer-Verlag: Berlin, 1981, Vol. 1.

[7] Gates, B.C.; Katzer, J. R.; Schuit, G.C. A. Chemistry of Catalytic Processes, McGraw-ill: New York, 1979.

[8] Paal, Z.; Uszkurat, A. I.; Olivier, S.; Gherin, M.; Kappenstein, C. Temperature - programmed reduction studies of platinum-tin catalysts. J. Catal., 1997, 168, 164-172. 
[9] Carvalho, L.; Pieck, C.; Rangel, M.; Figoli, N.; Vera, C.; Parera, J. Effect of solvent used during preparation on properties of $\mathrm{Pt}$ and Pt-Sn $/ \mathrm{Al}_{2} \mathrm{O}_{3}$ catalysts. Appl. Catal. A, 2004, 269, 105-114.

[10] Barias, O.; Olmen, A.; Blekkan, E. A. Propane dehydrogenation over supported Pt and Pt-Sn catalysts. J. Catal., 1996, 158,1-16.

[11] Li, Y.; Klabunde, K.; Davis, B. Characterization of platinum-tin catalysts supported on alumina and titania. J. Catal., 1992, 128, 18 .

[12] Srinivasan, R.; Davis, B. Electron micro-diffraction study of Pt-Snalumina reforming catalysts. Appl. Catal. A, 1992, 87, 45-52.

[13] Riad, M. Pt-Sn catalysts, preparation and characterization. Petrol. Sci. Technol., 2008, 26, 757-768.

[14] Young, J.F.; Gillard, R.D.; Wilkinson, G. Preparation, characterization and catalytic measurements of platinum-tin catalysts. $J$. Chem. Soc., 1964, 51, 76-84.

[15] Baronetti, G. T.; de Miguel, S.R.; Scelza, O.A.; Fritzler, M.A.; Castro, A. Pt-Sn $/ \mathrm{Al}_{2} \mathrm{O}_{3}$ catalysts: studies of impregnation step. Appl. Catal. A, 1985, 19, 77-90.

[16] Jin, L. Preparation of platinum -tin catalysts by different methods. Appl. Catal. A, 1991, 72, 33-39.

[17] Komiyama, M. Catalytic reforming of n-heptane on platinum-tin catalysts. Catal. Rev. Sci. Eng., 1995, 27, 341-350.

[18] Inui, T.; Miyake, T. Influence of water in the reaction stage of oxygen adsorbed platinum-tin supported on alumina. J. Catal., 1984, 86, 446-453.

[19] Huang, Y. J.; Fung, S.C. The effect of chloride and water vapour on the Pt-Ir reforming catalyst. J. Catal., 1991, 131, 378-391.

[20] Balakrishman, K.; Schwank, J. Chemisorptions studies of bimetallic platinum-tin catalysts. J. Catal., 1991, 127, 287-293.

[21] Humblot, F.; Candy, J. P.; Le Peltier, F.; Didillon, B.; Basset, J. M. Surface structure and catalytic performance of platinum-tin catalysts. J. Catal., 1998, 179, 459-468.
[22] Lieske, H.; Volter, J. Platinum-Tin reforming catalysis : Activity and selectivity in hydrocarbon reaction. J. Catal., 1984, 90, 96-101.

[23] Kappenstein, C.; Guerin, M.; Lazar, K.; Matusek, K.; Paal, Z. Xray diffraction and electron microscop studied of platinum-tin catalysts. J. Chem. Soc. Faraday Trans., 1998, 94, 2463-2476.

[24] Brunauer, S.; Deming, L.S.; Deming, W.E.; Teller, E.E. Porosity and texture analysis. Am. Chem. Soc., 1940, 62, 1723-1732.

[25] De Boer, J.H.; Linen, B.G.; Osniga, T. J. Microporosity and surface area determination. ibid., 1965, 4, 319-327.

[26] Lee, C.K. Characterization of platinum catalysts by electron microscopy. J. Chem. Eng., 2001, 34, 724-735.

[27] Mills, G.A.; Heinemann, H.; Milleken, T.H.; Oblad, A.G. Catalytic mechanism. Ind. Eng. Chem., 1953, 45, 134-144.

[28] Lui, H.; Lei, G. D.; Sachtler, W. M. H. Platinum-tin complex and its application on catalysis. Appl. Catal. A, 1996, 46, 165-173.

[29] Bishara, A.; Murad, K.; Stanislaus, A.; Ismail, M.; Hussain, S. Chlorine leaching studies on the platinum reforming catalysts. Appl. Catal. A, 1983, 7, 337-385.

[30] Salmones, J.; Wang, J-A.; Galicia, J.A.; Aguilar-Rios, G. Effect of particle size on the pore structure of platinum catalysts. G. J. Mol. Catal. A, 2002, 184, 203-215.

[31] Sharma, L.D.; Kumer, M.; Saxena, A.; Chand, M.; Gupta, J npentane isomerization on Pt catalysts. . J. Mol. Catal. A, 2002, 185, 135-140.

[32] Van Broekhoven, E.; Schoonhoven, J.; Ponec, V. On the mechanism for platinum catalyzed reduction reaction. Surf. Sci., 1985, 156, 899-908.

[33] Smith, J. Chemical Engineering Kinetics, $3^{\text {rd }}$ ed.; McGraw-Hill book Co: New York, 1981.

(C) Riad and Mikhail.; Licensee Bentham Open.

This is an open access article licensed under the terms of the Creative Commons Attribution Non-Commercial License (http://creativecommons.org/licenses/by$\mathrm{nc} / 3.0 /$ ) which permits unrestricted, non-commercial use, distribution and reproduction in any medium, provided the work is properly cited. 